\title{
Factors determining symptoms in heart failure: comparison of fast and slow exercise tests
}

\author{
DAVID P LIPKIN, * RUDOLPH CANEPA-ANSON, MICHAEL R STEPHENS, \\ PHILIP A POOLE-WILSON
}

\section{From the Cardiothoracic Institute and National Heart Hospital, London}

SUMMARY Factors determining the symptoms of breathlessness and fatigue in patients with congestive heart failure were investigated by comparing the response to slow and fast exercise. Symptom limited oxygen consumption (maximal); minute ventilation, mean pulmonary capillary wedge pressure; and arterial blood gases, $\mathrm{pH}$, and lactate concentrations were measured during treadmill exercise using a slow protocol in 25 men (age 34-67 years) with congestive heart failure (New York Heart Association class II-III). Ten of these patients were also exercised according to a rapid protocol. Exercise was terminated by fatigue in 23/25 patients after the slow test and by breathlessness in all patients after the rapid test. Exercise capacity (maximal oxygen consumption and exercise duration) was not related to resting or exercise pulmonary capillary wedge pressure or the change in pulmonary capillary wedge pressure during exercise, nor was there any difference in pulmonary capillary wedge pressure at the end of exercise within individuals between the fast and slow tests. Minute ventilation was greater (51 vs $431 / \mathrm{min}$ ), peak exercise lactate concentration higher $(3.7$ vs $2.2 \mathrm{mmol} / 1)$, and the change in $\mathrm{pH}$ from the resting state was greater $(0.06$ vs 0.02$)$ during the rapid test than during the slow test. The sensation of breathlessness in congestive heart failure is not simply related to raised pulmonary capillary wedge pressure, but may in part be due to stimulation of peripheral chemoreceptors in response to metabolic acidosis.

The cause of exercise intolerance in congestive heart failure is poorly understood. Patients treated with diuretics are limited more by fatigue than by breathlessness. Several studies have suggested that fatigue is related to an inadequate oxygen supply to skeletal muscle, ${ }^{1-3}$ because during exercise patients with heart failure have a reduced cardiac output, an early increase in lactate concentration, and augmented limb oxygen extraction. ${ }^{3}$ Common experience suggests that untrained normal subjects performing rapid exercise (for example running) often stop because of breathlessness, whereas when they exercise slowly (for example walking) they stop because of fatigue. In this study we have investigated whether the response to exercise in patients with congestive heart failure is similar, and if so whether differences in the metabolic, haemodynamic, and ventilatory re-

Requests for reprints to Professor Philip A Poole-Wilson, Cardiothoracic Institute and National Heart Hospital, 2 Beaumont Street, London W1N 2DX.

^Present address: Hammersmith Hospital, Du Cane Road, London W12 OH5. Accepted for publication 11 February 1986 sponses to two forms of exercise can explain the variable sensations of breathlessness and fatigue.

\section{Patients and methods}

\section{STUDY GROUP}

Patients were eligible for the study if they had stable symptomatic heart failure for more than three months with exercise intolerance due to fatigue or dyspnoea. In addition the patients we studied had radiological evidence of cardiomegaly and left ventricular ejection fraction $<45 \%$ on radionuclide or echocardiographic investigation. Twenty five men (mean age 50 years (range 34-67)) entered the study. The cause of heart failure was coronary artery disease in 15, dilated cardiomyopathy in eight, and hypertensive heart disease in two. Six patients were in class II and 19 in class III of the New York Heart Association classification. Patients were excluded if they had myocardial ischaemia or ventricular arrhythmias on exercise testing, obstructive valvar heart disease, pulmonary disease (documented by pulmonary function tests), or an inability to exercise for any reason other than dyspnoea or fatigue. 
PROTOCOL

To familiarise the patient with the exercise protocols, rapid and slow exercise tests were each performed twice in the two days before the study. Exercise was performed on a treadmill. Stages 1-4 consisted of treadmill speeds of $1,1.5,2$, and 2.5 $\mathrm{mph}$ on the level. Stages 4-9 consisted of a treadmill speed of $2.5 \mathrm{mph}$ and gradients of $2 \cdot 5,5,7 \cdot 5,10$, and $12.5 \%$. In the slow exercise protocol stages lasted 6 min. The rapid exercise protocol consisted of a sudden increase in workload from rest to that level of exercise at which exercise stopped during the practice slow exercise tests. The patient was maintained at that workload for $3 \mathrm{~min}$. The workload was then increased in stages every $2 \mathrm{~min}$. We have previously shown that after a change in workload, oxygen consumption reaches $95 \%$ and $100 \%$ of the steady state value within 2 and 3 minutes respectively. ${ }^{4}$

A Swan-Ganz catheter was inserted into a subclavian vein under local anaesthesia and advanced into the pulmonary artery and a TF14 catheter was inserted into the brachial artery under local anaesthesia. All patients were exercised on the slow protocol. Ten patients were exercised on the slow and rapid protocol in a randomised order on the same day. The second exercise test was performed $4 \mathrm{~h}$ after the first test. Oxygen consumption, carbon dioxide production, and minute ventilation were determined at rest and during exercise by a mass spectrometer (Airspec 200 MGA) and an online computer as previously described. ${ }^{4}$ Measurements were made every second and results were averaged over a 30 s period.

The anaerobic threshold was determined noninvasively from a graph of oxygen consumption against carbon dioxide production. A straight line of best fit was drawn through all points below $50 \%$ of maximal oxygen consumption attained. The anaerobic threshold was recorded as the level of oxygen consumption at which subsequent points began to deviate from this line. This technique provides results comparable to those obtained by graphical analysis with a computer. ${ }^{4}$ Pulmonary artery wedge pressure was recorded at end expiration and pulmonary artery and arterial blood samples were obtained (for the determination of oxygen saturation and lactate concentration) at rest, at the end of each stage of exercise, and at maximal exercise. Mean and phasic arterial blood pressures were recorded continuously.

Arterial blood for lactate determination was deproteinised with cold perchloric acid and assayed by a spectrophotometric technique. Oxygen saturation of blood was determined by a reflectometer (American Optical Corporation). Haemoglobin concentration was measured by a Coulter counter. Blood oxygen content was calculated by multiplying haemoglobin concentration by 1.34 ( $\mathrm{ml} / \mathrm{g}$ haemoglobin) and by per cent saturation. Arteriovenous oxygen difference was calculated as the arterial oxygen content minus pulmonary artery oxygen content. Cardiac output was calculated by the Fick principle as oxygen consumption divided by arteriovenous oxygen difference. This method has been validated against the thermodilution technique. ${ }^{5}$

\section{REPRODUCIBILITY}

Measurement of maximal oxygen consumption and anaerobic threshold and plasma lactate concentration has been shown to be reproducible. ${ }^{6}$ The reproducibility of cardiac output and pulmonary capillary wedge pressure was assessed in five patients who performed two slow exercise tests within a 24 hour period. There was less than 12\% variability in the measurement of cardiac output and pulmonary capillary wedge pressure recorded during the two exercise tests in the same patient.

\section{STATISTICAL METHODS}

Data are expressed as mean (SEM) unless otherwise stated. Statistical analysis was performed by paired Wilcoxon test for paired data and by linear regression.

\section{Results}

All patients were taking diuretics. The mean dose of frusemide was $45 \mathrm{mg}$ for those patients in New York Heart Association class II and $110 \mathrm{mg}$ for those in class III. Vasodilator treatment included captopril $(n=6)$ and nitrates $(n=5)$. Four patients, all of whom were in atrial fibrillation, were taking digoxin.

\section{EXERCISE CAPACITY AND HAEMODYNAMIC} RESPONSE TO SLOW EXERCISE

Exercise testing was completed without incident in all patients. Exercise was terminated by fatigue in 18 patients and fatigue and breathlessness in five patients. Only two patients claimed that they stopped because of severe breathlessness alone.

Maximal oxygen consumption $(\mathrm{ml} / \mathrm{kg} / \mathrm{min}$ ) for patients in New York Heart Association class II was $19(1.7)$, and class III $13(0.9)$, which is considerably below the normal range for this age group. ${ }^{7}$ Values recorded are symptom limited maximal oxygen consumption. It was not possible to demonstrate a genuine plateau of oxygen consumption with increasing workload because patients stopped exercise before this point was reached.

The haemodynamic and ventilatory changes were analysed by regression analysis. There was no correlation between resting, maximal, or change in pul- 
Table 1 Haemodynamic and ventilatory changes during the slow exercise protocol in patients with heart failure

\begin{tabular}{|c|c|c|c|c|c|c|c|}
\hline \multirow[t]{2}{*}{ Patient } & \multirow{2}{*}{$\begin{array}{l}\dot{V} 0_{2} \max \\
(\mathrm{ml} / \mathrm{kg} / \mathrm{min})\end{array}$} & \multirow{2}{*}{$\begin{array}{l}\text { Exercise } \\
\text { duration } \\
\text { (min) }\end{array}$} & \multicolumn{3}{|c|}{$P C W P(\mathrm{~mm} \mathrm{Hg})$} & \multicolumn{2}{|c|}{ Cardiac index $\left(l / \min / \min ^{2}\right)$} \\
\hline & & & Rest & Exercise & Change & Rest & Exercise \\
\hline $\begin{array}{c}1 \\
2 \\
3 \\
4 \\
5 \\
6 \\
7 \\
8 \\
9 \\
10 \\
11 \\
12 \\
13 \\
14 \\
15 \\
16 \\
17 \\
18 \\
19 \\
20 \\
21 \\
22 \\
23 \\
24 \\
25 \\
\text { Mean } \\
\text { SD }\end{array}$ & $\begin{array}{l}25 \\
17 \\
22 \\
12 \\
11 \\
13 \\
14 \\
20 \\
11 \\
12 \\
11 \\
12 \\
14 \\
11 \\
18 \\
17 \\
21 \\
14 \\
19 \\
15 \\
10 \\
10 \\
22 \\
13 \\
16 \\
15 \cdot 3 \\
4 \cdot 3\end{array}$ & $\begin{array}{l}64 \\
34 \\
64 \\
22 \\
33 \\
34 \\
46 \\
17 \\
24 \\
17 \\
18 \\
16 \\
44 \\
17 \\
40 \\
40 \\
59 \\
34 \\
26 \\
24 \\
17 \\
19 \\
17 \\
17 \\
30 \\
31 \\
15\end{array}$ & $\begin{array}{r}4 \\
24 \\
17 \\
20 \\
22 \\
13 \\
10 \\
16 \\
22 \\
12 \\
10 \\
25 \\
25 \\
10 \\
10 \\
14 \\
8 \\
12 \\
8 \\
15 \\
32 \\
34 \\
22 \\
11 \\
14 \\
16 \\
7\end{array}$ & $\begin{array}{r}18 \\
30 \\
30 \\
26 \\
29 \\
28 \\
20 \\
36 \\
23 \\
25 \\
24 \\
29 \\
42 \\
21 \\
21 \\
23 \\
16 \\
42 \\
13 \\
28 \\
32 \\
36 \\
30 \\
18 \\
44 \\
27 \\
8\end{array}$ & $\begin{array}{r}14 \\
6 \\
13 \\
6 \\
7 \\
15 \\
10 \\
20 \\
1 \\
13 \\
14 \\
4 \\
17 \\
11 \\
11 \\
9 \\
8 \\
30 \\
5 \\
13 \\
0 \\
2 \\
8 \\
7 \\
30 \\
11 \\
7 \cdot 3\end{array}$ & $\begin{array}{l}2.1 \\
1.7 \\
2.4 \\
1.5 \\
2.2 \\
1.9 \\
2.2 \\
2.6 \\
2.8 \\
2.4 \\
2.2 \\
1.7 \\
2.2 \\
1.5 \\
3.4 \\
3.5 \\
1.6 \\
2.1 \\
2.7 \\
1.7 \\
1.7 \\
1.9 \\
2.0 \\
2.0 \\
2.2 \\
2.2 \\
0.5\end{array}$ & $\begin{array}{l}10 \\
4.1 \\
6.6 \\
3.1 \\
3.3 \\
3.0 \\
4.5 \\
5.9 \\
3.5 \\
3.3 \\
3.3 \\
2.8 \\
3.9 \\
3.7 \\
7.0 \\
6.5 \\
4.6 \\
4.3 \\
4.7 \\
3.0 \\
2.7 \\
3.4 \\
5.5 \\
5.0 \\
5.6 \\
4.5 \\
1.7\end{array}$ \\
\hline
\end{tabular}

$\mathrm{V}_{2}$ max, maximal oxygen consumption; PCWP, pulmonary capillary wedge pressure.

monary capillary wedge pressure and maximal oxygen consumption $(\mathrm{r}=-0 \cdot 38$. $\mathrm{r}=-0 \cdot 19$, and $\mathrm{r}=\mathbf{0} \cdot 12$ respectively) (Fig. 1) or exercise duration $(r=-0.36, r=0.16, r=-0.15)$. In contrast, maximal cardiac index on exercise did correlate with maximal oxygen consumption and exercise duration $(r=0.77, p<0.0001$ and $r=0.60, p<0.001$ respectively). Cardiac index at rest did not correlate with maximal oxygen consumption or exercise duration $(r=0.21, r=0.18$ respectively) (Table 1$)$.

\section{VENTILATORY HAEMODYNAMIC AND}

METABOLIC RESPONSE TO FAST EXERCISE

Ten patients exercised by both the slow and fast exercise protocols, so that within patient comparison of responses to these tests was possible. All $10 \mathrm{pa}-$ tients were among those who stopped exercise on the slow protocol because of fatigue. On the fast exercise protocol these patients stopped exercise because of severe breathlessness. Maximal oxygen consumption correlated with maximal cardiac index $(r=0.6, p<0.05)$ with maximal pulmonary capillary wedge pressure (Fig. 2) $(r=-0 \cdot 1)$. Patients were able to exercise to a greater workload on the fast test (mean of 2.2 stages further than on the slow test). Minute ventilation at peak exercise was significantly higher during the fast test than during the slow test ( 51 vs $43 \mathrm{l} / \mathrm{min}, \mathrm{p}<0.01$ ). Furthermore the mixed expired oxygen concentration at peak exercise was significantly greater during the rapid protocol than during the slow protocol $(17.6$ vs $17.0 \%, \mathrm{p}<0.01)$, suggesting that the sensation of breathlessness was associated with a greater degree of hyperventilation. Maximal oxygen consumption was greater at the end

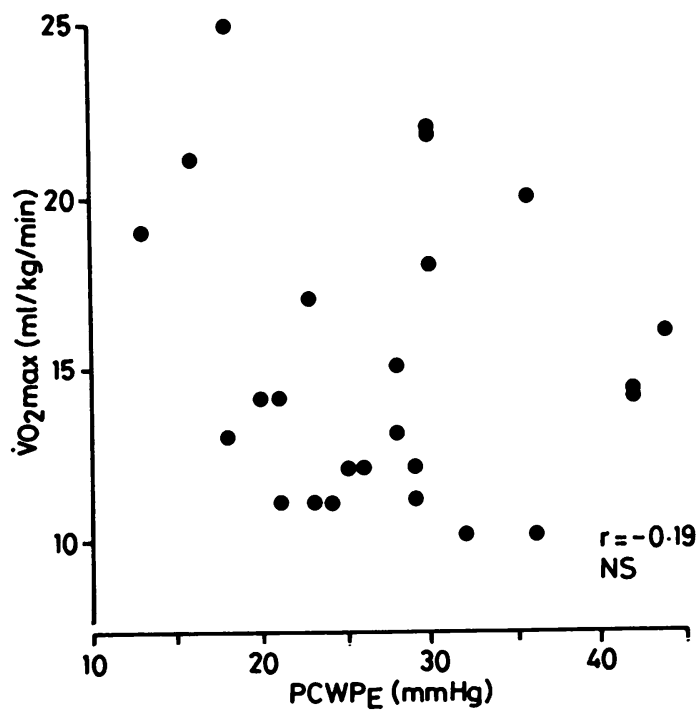

Fig. 1 Relation between maximal oxygen consumption $\left(\mathrm{VO}_{2}\right.$ max) and maximal pulmonary capillary wedge pressure $\left(P C W P_{\mathrm{E}}\right)$ during the slow exercise test. 


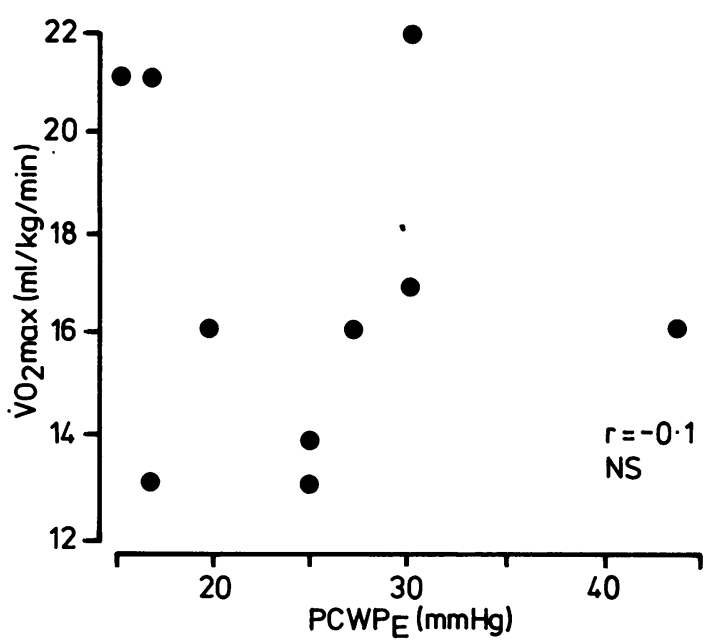

Fig. 2 Relation between maximal oxygen consumption $\left(\mathrm{VO}_{2}\right.$ max) and maximal pulmonary capillary wedge pressure $\left(P C W P_{\mathrm{E}}\right)$ during the rapid exercise test.

of the fast protocol than at the end of the slow proto$\operatorname{col}(16.8$ vs $14.9 \mathrm{ml} / \mathrm{kg} / \mathrm{min}, \mathrm{p}<0.01)$, as was anaerobic threshold (12 vs $11 \mathrm{ml} / \mathrm{kg} / \mathrm{min}, \mathrm{p}<0.01)$. Mean blood pressure at peak exercise was the same during the slow and fast protocols. Though the reasons for stopping exercise were different in the two tests the mean pulmonary capillary wedge pressure in the patients at peak exercise was the same in the two tests $(\mathrm{p}<0.3)$.

Arterial blood lactate concentration at peak exercise was higher and the change in arterial blood $\mathrm{pH}$ from the resting stage was greater during the fast test than during the slow test $(3.7$ vs $2.2 \mathrm{mmol} / \mathrm{l}$, $\mathrm{p}<0.01 ; 0.06$ vs $0.02, \mathrm{p}<0.01$ ) (Table 2).

\section{Discussion}

Patients with congestive heart failure frequently have limited exercise capacity because of fatigue and breathlessness. The present study has demonstrated that the symptom that ultimately terminates exercise depends on the type of exercise performed. Patients exercising on the fast protocol were stopped by breathlessness, yet when they exercised on the slow protocol fatigue was the limiting factor. We have obtained a similar result in a small pilot study of a different group of patients. ${ }^{8}$

The sensation of breathlessness was accompanied by objective changes in ventilatory gas exchange. Minute ventilation and mixed expired oxygen concentration were greater during the rapid test than during the slow exercise test, suggesting that the symptom of breathlessness was associated with a greater hyperventilatory response.

Many mechanisms have been put forward to account for breathlessness in patients with heart failure. Patients with congestive heart failure have an increased physiological and anatomical dead space. ${ }^{910}$ It has been suggested that the hyperventilatory response seen in these patients occurs because more respiratory effort is required to ventilate the dead space and maintain eucapnia. ${ }^{10} \mathrm{Com}-$ parisons made within patients indicate that this effect is unlikely to account for the different symptoms during slow and fast exercise tests.

Juxtapulmonary capillary receptors (J receptors) may be activated by lung stiffening, such as that which occurs with the accumulation of interstitial fluid, and this can result in tachypnoea and the sensation of breathlessness. ${ }^{11}$ Decreased lung compliance, however, does not correlate with the degree of

Table 2 Comparative haemodynamic, ventilatory, and metabolic changes during the rapid and slow exercise tests in patients with chronic heart failure

\begin{tabular}{|c|c|c|c|c|c|c|c|c|c|c|c|c|c|c|c|c|c|c|}
\hline \multirow[t]{2}{*}{ Patient } & \multicolumn{2}{|c|}{$\begin{array}{l}\dot{V} 0_{2} \max \\
(\mathrm{ml} / \mathrm{kg} / \mathrm{min})\end{array}$} & \multicolumn{2}{|c|}{$\begin{array}{l}\text { Anaerobic } \\
\text { threshold } \\
(\mathrm{ml} / \mathrm{kg} / \mathrm{min})\end{array}$} & \multicolumn{2}{|c|}{$\begin{array}{l}\text { Cardiac } \\
\text { index } \\
\left(l / m i n / m^{2}\right)\end{array}$} & \multicolumn{2}{|c|}{$\begin{array}{l}\text { Systemic } \\
B P(m m H g)\end{array}$} & \multicolumn{2}{|c|}{$\begin{array}{c}P C W P_{E} \\
\left(m m H_{g}\right)\end{array}$} & \multicolumn{2}{|c|}{$\begin{array}{l}\text { Minute } \\
\text { ventilation } \\
\text { (l/min) }\end{array}$} & \multicolumn{2}{|c|}{$\underset{p H}{\Delta A \text { Arterial }}$} & \multicolumn{2}{|c|}{$\underset{\left(\mathrm{mm} \mathrm{Hg}_{\mathrm{g}}\right.}{\triangle \mathrm{PaCO}_{2}}$} & \multicolumn{2}{|c|}{$\begin{array}{l}\text { Lactate } \\
\text { (mmol/l) }\end{array}$} \\
\hline & Slow & Fast & Slow & Fast & Slow & Fast & Slow & Fast & Slow & Fast & Slow & Fast & Slow & Fast & Slow & Fast & Slow & Fast \\
\hline $\begin{array}{c}1 \\
2 \\
3 \\
4 \\
5 \\
6 \\
7 \\
8 \\
9 \\
10 \\
\text { Mean } \\
\text { SE }\end{array}$ & $\begin{array}{l}19 \\
20 \\
14 \\
11 \\
21 \\
11 \\
13 \\
14 \\
11 \\
15 \\
15 \\
1\end{array}$ & $\begin{array}{l}21 \\
21 \\
16 \\
13 \\
21 \\
14 \\
16 \\
16 \\
13 \\
17 \\
17 \\
1\end{array}$ & $\begin{array}{r}14 \\
13 \\
11 \\
8 \\
19 \\
10 \\
10 \\
10 \\
10 \\
11 \\
11 \\
1\end{array}$ & $\begin{array}{r}15 \\
14 \\
11 \\
9 \\
19 \\
11 \\
11 \\
11 \\
11 \\
12 \\
12 \\
1\end{array}$ & $\begin{array}{l}4 \cdot 7 \\
5 \cdot 9 \\
4 \cdot 4 \\
3 \cdot 7 \\
4 \cdot 6 \\
3 \cdot 3 \\
3 \cdot 0 \\
4 \cdot 3 \\
3 \cdot 3 \\
3 \cdot 0 \\
4 \cdot 0 \\
0.3\end{array}$ & $\begin{array}{l}4.7 \\
5.5 \\
4.5 \\
4.2 \\
4.5 \\
3.5 \\
3.7 \\
5.5 \\
3.5 \\
3.3 \\
4.3 \\
0.2\end{array}$ & $\begin{array}{r}95 \\
93 \\
96 \\
69 \\
86 \\
70 \\
108 \\
104 \\
83 \\
69 \\
87 \\
4\end{array}$ & $\begin{array}{r}102 \\
93 \\
96 \\
75 \\
88 \\
71 \\
100 \\
106 \\
74 \\
67 \\
87 \\
4\end{array}$ & $\begin{array}{r}13 \\
36 \\
20 \\
21 \\
16 \\
25 \\
28 \\
42 \\
28 \\
30 \\
26 \\
3\end{array}$ & $\begin{array}{l}15 \\
30 \\
20 \\
17 \\
17 \\
25 \\
27 \\
44 \\
25 \\
30 \\
25 \\
3\end{array}$ & $\begin{array}{r}35 \\
63 \\
41 \\
37 \\
49 \\
39 \\
41 \\
47 \\
36 \\
41 \\
43 \\
3\end{array}$ & $\begin{array}{l}42 \\
77 \\
46 \\
49 \\
49 \\
49 \\
52 \\
49 \\
45 \\
48 \\
51\end{array}$ & $\begin{array}{l}0.05 \\
0.02 \\
0.02 \\
0.04 \\
0.03 \\
0.02 \\
0.03 \\
0.00 \\
0.01 \\
0.02 \\
0.02 \\
0.01\end{array}$ & $\begin{array}{l}0.1 \\
0.06 \\
0.08 \\
0.06 \\
0.03 \\
0.04 \\
0.04 \\
0.07 \\
0.05 \\
0.03 \\
0.06 \\
0.01\end{array}$ & $\begin{array}{r}+1 \\
-1 \\
0 \\
+4 \\
-2 \\
0 \\
-5 \\
-4 \\
-1 \\
+1 \\
-1 \\
0\end{array}$ & $\begin{array}{r}0 \\
0 \\
-3 \\
+1 \\
-2 \\
0 \\
-2 \\
0 \\
-2 \\
-4 \\
-1 \\
0\end{array}$ & $\begin{array}{l}2 \cdot 2 \\
2.4 \\
2.5 \\
2 \cdot 6 \\
2.3 \\
1.0 \\
2.3 \\
2.5 \\
1 \cdot 7 \\
2.3 \\
2 \cdot 2 \\
0.1\end{array}$ & $\begin{array}{l}3.8 \\
3.9 \\
4.2 \\
3.5 \\
4.2 \\
2.5 \\
5.1 \\
3.5 \\
3.0 \\
3.1 \\
3.7 \\
0.2\end{array}$ \\
\hline$p$ & \multicolumn{2}{|c|}{$<0.01$} & \multicolumn{2}{|c|}{$<0.01$} & \multicolumn{2}{|c|}{ NS } & \multicolumn{2}{|c|}{ NS } & \multicolumn{2}{|c|}{ NS } & \multicolumn{2}{|c|}{$<0.01$} & \multicolumn{2}{|c|}{$<0.01$} & \multicolumn{2}{|c|}{ NS } & \multicolumn{2}{|c|}{$<0.01$} \\
\hline
\end{tabular}

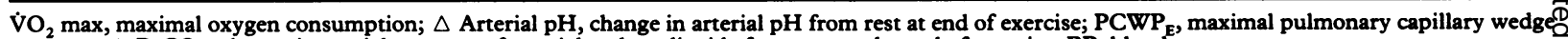
pressure; $\triangle \mathrm{PaCO}_{2}$, change in partial pressure of arterial carbon dioxide from rest at the end of exercise; $\mathrm{BP}$, blood pressure. 
dyspnoea ${ }^{12-14}$ and only small increases in pulmonary blood volume and pulmonary extravascular fluid have been demonstrated in patients with left ventricular dysfunction. ${ }^{15}$ In the present study there was no correlation between resting or maximal pulmonary capillary wedge pressure and maximal oxygen consumption in patients exercised on the slow protocol; this accords with the studies by Franciosa et al. ${ }^{16}{ }^{17}$ Furthermore, there was no difference in maximal pulmonary capillary wedge pressure at the end of the slow and fast exercise tests. These findings suggest that a high pulmonary capillary wedge pressure does not limit exercise tolerance and is not the major factor responsible for the sensation of breathlessness in patients with congestive heart failure. The interpretation based on this data should not be applied to patients with acute onset of left ventricular failure where a high left atrial pressure results in pulmonary oedema and breathlessness.

If a respiratory cause was primarily responsible for the exercise limitation in congestive heart failure, a fall in arterial oxygen saturation would be expected. We and others have shown normal arterial oxygen saturation during exercise in these patients. ${ }^{6} 18$

An alternative mechanism may be operating during the metabolic changes that occur during exercise. Plasma lactate concentration is increased primarily as a consequence of an inadequate supply of oxygen to metabolising tissue, ${ }^{19}$ with resultant anaerobic metabolism. Skeletal muscle blood flow is reduced in patients with congestive heart failure and this accounts for the early appearance of lactate in the femoral vein on exercise. ${ }^{3}$ Fast twitch muscle fibres produce lactate despite an adequate supply of oxygen $^{20}$ and they are recruited for short bursts of strenuous muscle activity. A reduction of blood flow to the liver and diminished hepatic metabolism may contribute to the rise of blood lactate concentration. Rapid exercise will thus result in a greater rate of production of lactate which exceeds its rate of metabolism by the liver; hence the higher blood lactate concentration that was seen at the end of the fast protocol.

Lactate is buffed by bicarbonate in the blood producing carbon dioxide in excess of that resulting from aerobic metabolism. Arterial carbon dioxide tension was unchanged from the resting value at the end of both exercise protocols, yet arterial blood $\mathrm{pH}$ was significantly lower at the end of the fast test than at the end of the slow test; this is consistent with the greater rise in plasma lactate concentration seen during this test.

The ventilatory response in normal people during exercise may be related to feedback loops that monitor the changes in arterial $\mathrm{pH}$ and carbon dioxide tension and depend on intact carotid body receptors. $^{2122}$ The ventilatory response to exercise and exercise capacity can be modified by alterations of $\mathrm{pH}$ and carbon dioxide tension in arterial blood. ${ }^{23}$ The present study shows that the sensation of breathlessness was associated with a rapid rise in plasma lactate concentration and fall in arterial $\mathrm{pH}$.

Such observations do not necessarily imply cause and effect nor that the hyperventilatory response is solely dependent on the metabolic changes in the blood on exercise. Patients with McArdle's disease cannot produce lactic acid yet they hyperventilate on exercise. ${ }^{24}$ It has been suggested that the hyperventilatory response in these patients may be induced by skeletal muscle pain. ${ }^{25}$ It is unlikely that a local stimulus in muscle mediated by neural mechanisms ${ }^{26}$ is solely responsible for the sensation of breathlessness in normal people and patients with congestive heart failure, because a hyperventilatory response has been shown to occur in patients with spinal transection. ${ }^{27}$ The present results are consistent with the idea that the sensation of breathlessness that occurs in patients with congestive heart failure during rapid exercise is in part the consequence of the rapid rise in blood lactate concentration and fall in $\mathrm{pH}$ that stimulate the hyperventilatory response.

Fatigue is the second major symptom of patients with heart failure. This study demonstrates that exercise tolerance in congestive heart failure is related to maximal cardiac output during exercise. Wilson et al demonstrated that patients with congestive heart disease stopped exercise because of fatigue when a critical level of muscle underperfusion occurred and they concluded that the low maximal exercise capacity of patients with congestive heart failure was the result of impaired nutritive flow to skeletal muscle. ${ }^{3}$ Though the results of this study accord with that idea, other factors may be relevant. Most patients stopped exercise on the slow protocol because of fatigue. When 10 of these patients were exercised on the fast protocol, however, they stopped exercise at significantly higher cardiac outputs and maximal oxygen consumption, yet with the same mean arterial blood pressure, than when they were exercised on the slow protocol.

There are two explanations for this unexpected finding. The sensation of fatigue in congestive heart failure is not dependent solely on impaired nutritive flow to exercising muscle. Rise in body temperature, boredom, and lack of motivation may have ended the exercise test prematurely. Alternatively, prolonged exercise may be associated with an increase in skin blood flow to offset the rise in body temperature and maintain thermoregulatory control. This would divert blood from skeletal muscle and lead to the earlier 
development of anaerobic metabolism and a fall in intracellular $\mathrm{pH}$ as lactic acid accumulates within the cell. Presumably the rate of lactate production is nearly matched by the rate of lactate clearance and hence there is only a small rise in blood lactate concentration. Intracellular acidosis is closely related to and may be partly responsible for muscle fatigue. ${ }^{28-30}$

We have demonstrated that the design of an exercise protocol is important when assessing the maximal exercise capacity of patients with congestive heart failure. Though a steady state may not be reached with protocols with stages of short duration, ${ }^{31}$ if prolonged exercise testing is used to ensure a steady state at each stage of the exercise test symptom limited maximal oxygen consumption, anaerobic threshold, and maximal cardiac output may be underestimated. Similar observations were recently made by Buchfuhrer et al in normal people; as a result they suggested selecting work rate increments to bring the subjects to the limit of their exercise tolerance in about 10 minutes. ${ }^{32}$ Further studies are required to evaluate the best exercise protocol for studying exercise capacity of patients with heart failure; the present study suggests that short exercise protocols with rapid increases in workload are desirable.

This study has shown that the symptoms limiting exercise tolerance in patients with congestive heart failure depend on the type of exercise performed and that such symptoms are independent of changes in pulmonary capillary wedge pressure. Metabolic changes may contribute to the sensation of breathlessness during rapid forms of exercise. Symptom limited maximal oxygen consumption and peak cardiac output recorded during exercise are affected by the length of the exercise protocol. The design of exercise protocols for the assessment of patients with congestive heart failure must take these factors into account.

\section{References}

1 Huckabee WE, Judson WE. The role of anaerobic metabolism in the performance of mild muscular work. Relationship to oxygen consumption and cardiac output and the effects of congestive heart failure. $\mathcal{F}$ Clin Invest 1958; 37: 1577-92.

2 Zelis R, Nellis SH, Longhurst J, Lee G, Mason DT. Abnormalities in the regional circulations accompanying congestive heart failure. Prog Cardiovasc Dis 1975; 18: 187-99.

3 Wilson JR, Martin JL, Schwartz D, Ferraro N. Exercise intolerance in patients with chronic heart failure: role of impaired skeletal muscle nutritive flow. Circulation 1984; 69: 1079-87.

4 Lipkin DP, Perrins J, Poole-Wilson PA. Respiratory gas exchange in the assessment of patients with im- paired ventricular function. Br Heart $\mathcal{F} 1985$; 54: 321-8.

5 Lipkin DP, Poole-Wilson PA. Measurement of cardiac output during exercise by the thermodilution and direct Fick techniques in patients with chronic congestive heart failure. Am $\mathcal{F}$ Cardiol 1985; 56: 321-4.

6 Weber KT, Janicki JS. Lactate prediction during maximal and submaximal exercise in patients with chronic heart failure. F Am Coll Cardiol 1985; 6: 717-24.

7 Mitchell JH, Sproule BJ, Chapman CB. The physiological measuring of the maximal oxygen uptake test. f Clin Invest 1958; 37: 538-47.

8 Canepa-Anson R, Reid C, Gibbs S, et al. Limiting symptoms in chronic heart failure are dependent on the rate of increase of workload and independent of haemodynamics. Clin Sci 1983; 66: 51P.

9 Wilson JR, Ferraro N. Exercise intolerance in patients with chronic left heart failure: relation to oxygen transport and ventilatory abnormalities. Am f Cardiol 1983; 51: 1358-63.

10 Rubin SA, Brown HV. Ventilation and gas exchange during exercise in severe chronic heart failure. Am Rev Respir Dis 1984; 129: 563-4.

11 Paintal AS. Mechanism of stimulation of type J pulmonary receptors. F Physiol (Lond) 1969; 203: 511-32.

12 Frank RN, Cugell DW, Caensler EA, Ellis LB. Ventilatory studies in mitral stenosis. Am f Med 1953; 15: 60-75.

13 Brown CC Jr, Fry DL, Ebert RV. The mechanics of pulmonary ventilation in patients with heart disease. Am $\mathcal{F}$ Med 1954; 17: 438-46.

14 Hayward GW, Knott JMS. The effect of exercise on lung distensibility and respiratory work in mitral stenosis. Br Heart F 1955; 17: 303-11.

15 Austin SM, Schreiner BF, Shah PM, Yu PN. Acute effects of increase pulmonary vascular distending pressure on pulmonary blood volume and pulmonary extravascular fluid volume in man. Circulation 1976; 53: 356-63.

16 Franciosa JA. Functional capacity of patients with chronic left ventricular failure: relationship of bicycle exercise performance to clinical and haemodynamic characterisation. Am f Med 1979; 67: 460-6.

17 Franciosa JA, Leddy CL, Wilen M, Schwartz DE. Relation between haemodynamic and ventilatory responses in determining exercise capacity in severe congestive heart failure. Am $\mathcal{f}$ Cardiol 1984; 53: 127-34.

18 Rubin SA, Brown HV, Swan HJC. Arterial oxygen and arterial oxygen transport in chronic myocardial failure at rest, during exercise and after hydralazine treatment. Circulation 1982; 66: 143-8.

19 Karlsson J, Jacobs I. Onset of blood lactic accumulation during muscular exercise as a threshold concept. Theoretical considerations. Int f Sports Med 1982; 3: 190-201.

20 Holloszy J. Adaptations of muscular tissue to training. Prog Cardiovasc Dis 1976; 8: 445-58.

21 Wasserman K, Whipp BJ, Koyal SN, Cleary MG. Effect of carotid body resection on ventilation and base control during exercise. F Appl Physiol 1975; 39: 354-8.

22 Wasserman K, Whipp BJ, Davis JA. Respiratory physiology of exercise: metabolism, gas exchange and venti- 
latory control. Int Rev Physiol 1981; 23: 189-90.

23 Jones NL, Sutton JR, Taylor R, Toews CJ. Effect of $\mathrm{pH}$ on cardiorespiratory and metabolic responses to exercise. 7 Appl Physiol 1977; 43: 959-64.

24 Hagberg JM, Coyle EF, Carroll JE, Muller JM, Martin $\mathrm{WH}$, Brooke $\mathrm{MH}$. Exercise hyperventilation in patients with McArdle's disease. F Appl Physiol 1982; 52: 991-4.

25 Whipp BJ. Exercise hyperventilation of patients with McArdle's disease. f Appl Physiol 1983; 55: 1638-9.

26 Weissman ML, Whipp BJ, Huntsman DJ, Wasserman K. Role of neural afferents from working limbs on exercise dyspnoea. F Appl Physiol 1980; 49: 239-48.

27 Adams L, Frankl J, Garlick J, Guz A, Murphy K, Semple SJG. The role of spinal cord transmission in the ventilatory response to exercise in man. $\mathcal{F}$ Physiol (Lond) 1984; 355: 85-97.
28 Dawson MJ, Gardian DG, Wilkie DR. Muscular fatigue investigated by phosphorus nuclear magnetic resonance. Nature 1978; 274: 861-6.

29 Karlson J, Salten B. Lactate ATP and CP in working muscles during exhaustive exercise in man. $\mathcal{F} A p p l$ Physiol 1970; 29: 598-604.

30 Harmenson L. Effect of metabolic changes on force generation in skeletal muscle during maximal exercise. In: Porter R, Whelan J, eds. Ciba Foundation Symposium: 82. London: Pitman Medical, 1981: 75.

31 Whipp BJ, Wasserman K. Oxygen uptake kinetics for various intensities of workload. $\mathcal{F}$ Appl Physiol 1972; 33: 351-6.

32 Buchfuhrer MJ, Hansen JE, Robinson TE, Sue DY, Wasserman K, Whipp BJ. Optimising the exercise protocol for cardiopulmonary assessment. $\mathcal{F}$ Appl Physiol 1983; 55: 1558-64. 